九州大学学術情報リポジトリ

Kyushu University Institutional Repository

\title{
Measurement of Strain Distributions in White Oak Boards during Drying Using a Digital Image Correlation Method
}

\section{Kang, Ho-Yang}

Department of Biobased Materials, College of Agriculture and Life Sciences, Chungnam National University

\section{Kang, Seog-Goo}

Department of Biobased Materials, College of Agriculture and Life Sciences, Chungnam National University

\section{Kang, Chun-Won}

Department of Housing Environmental Design, and Research Institute of Human Ecology, College of Human Ecology, Chonbuk National University

Matsumura, Junj i

Laboratory of Wood Science, Division of Sustainable Bioresources Science, Department of Agroenvironmental Sciences, Faculty of Agriculture, Kyushu University

https://doi.org/10.5109/26161

出版情報：九州大学大学院農学研究院紀要. 58 (1)，pp.55-58，2013-02. Faculty of Agriculture， Kyushu University

バージョン :

権利関係: 


\title{
Measurement of Strain Distributions in White Oak Boards during Drying Using a Digital Image Correlation Method
}

\author{
Ho-Yang KANG ${ }^{1}$, Seog-Goo KANG ${ }^{1}$, Chun-Won KANG ${ }^{2 *}$ \\ and Junji MATSUMURA ${ }^{3}$ \\ Laboratory of Wood Science, Division of Sustainable Bioresource Science, \\ Department of Agro-environmental Sciences, Faculty of Agriculture, \\ Kyushu University, Fukuoka 812-8581, Japan \\ (Received October 29, 2012 and accepted November 8, 2012)
}

\begin{abstract}
To understand the optical measurement and digital image correlation (DIC) visualization of strain distribution during wood drying and to optimize wood drying schedules, the drying behaviors of white oak specimens, a refractory species, were investigated using an optical measurement system and a DIC method.

White oak specimens were dried in a climate chamber, which was modified to be similar to a drying kiln. Strain distribution on the cross-sectional surface of the wood during drying was successfully visualized, and the position and timing of the stress reversals were detected. From the comparison of the strain distributions between mild and severe drying conditions, it was determined that the rheological deformation of wood under mild drying conditions is much more severe than under severe drying condition as the mild case required more time to dry.

These results could be used in the development of a new drying schedule or for optimizing an existing drying schedule.
\end{abstract}

Key words: strain distributions, optical measurement, DIC (digital image correlation) system

\section{INTRODUCTION}

Wood is a hygroscopic material, which means that the moisture content of wood changes with variation in the circumferential moisture conditions. During wood drying, moisture will evaporate and the wood volume will shrink due to moisture loss. However, the dimensional change in wood is non-uniform because wood is anisotropic and non-homogeneous. In addition, though conventional measurement methods can estimate the overall dimensional change of dried wood, it is difficult to estimate localized dimensional change because of the nonhomogeneous nature of wood.

With the development of optical measurement techniques using digital image correlation (DIC) and the efforts of wood scientists, local strain deformation can be visualized during wood drying (Schmidt, 2002: Muszyński, 2006; Muszyński et al., 2006).

Kang et al. (2011b) continuously estimated drying strain distributions during room temperature drying on a cross section of a white oak log using an optical measurement instrument and DIC method. They reported the detection of small cracks in the oak veneer and shrinkage of the moist wood when the moisture content of the wood was above the fiber saturation point. In addition,

\footnotetext{
1 Department of Biobased Materials, College of Agriculture and Life Sciences, Chungnam National University, Daejeon 305764 , Korea

2 Department of Housing Environmental Design, and Research Institute of Human Ecology, College of Human Ecology, Chonbuk National University, Jeonju 561-756, Korea

3 Laboratory of Wood Science, Division of Sustainable Bioresources Science, Department of Agro-environmental Sciences, Faculty of Agriculture, Kyushu University, Fukuoka 812-8581, Japan

* Corresponding author (E-mail: kcwon@jbnu.ac.kr)
}

they reported that highly wetted wood can swell slightly in the radial direction during the initial drying stage (Kang et al., 2011a).

When observing wood drying at the microscopic scale, shrinkage and microcracking were observed by in-situ observation using confocal laser scanning microscopy (Sakagami et al., 2007; Sakagami et al., 2009a; Sakagami et al., 2009b).

From these results, we suggest that the optical measurement technique and digital image correlation method can contribute to the understanding of the drying characteristics of refractory species such as white oak.

To confirm that the optical measurement technique and DIC method could accurately visualize locally-originated strain distributions during wood drying, we measured the three-dimensional strain distribution of white oak boards in a drying kiln using DIC.

\section{MATERIALS AND METHODS}

\section{Sample specimens}

Sample boards with dimensions of $30 \mathrm{~mm}$ (radial) $\times$ $100 \mathrm{~mm}$ (tangential) $\times 330 \mathrm{~mm}$ (longitudinal) were prepared from green quarter sawn white oak (Quercus alba) board. These boards were cut into three pieces in the longitudinal direction. The center board of the three specimens was used as the sample specimen, and the two end boards were used to form a dummy stack, as shown in Figure 1. The dimensions of the sample specimens used were $30 \mathrm{~mm}$ (radial) $\times 100 \mathrm{~mm}$ (tangential) $\times 100 \mathrm{~mm}$ (longitudinal). The cross and tangential sectional surfaces were coated with PVAc polymer to prevent moisture evaporation through them. Moisture transportation in the sample board was induced at the top and bottom surfaces (the longitudinal-radial planes) of the 
board to facilitate drying check observations. The side of the sample specimen that was turned toward the measuring lens was covered with spray paint to make speckles on the sample surface in order to obtain clear images.

\section{Experimental apparatus}

The experimental apparatus was similar to that used in a previous report (Kang et al., 2011a), and is shown in Figure 2. The measurement system consisted of a humidity chamber, a sample specimen housing, and an optical measurement system, which consists of two lenses and a digital image capture board. The DIC system used in this research was VIC3D made by Correlated Solutions, Inc., Columbia, SC, USA.

The sample specimens were stacked in the specimen housing as shown in Figure 2. Both the sample and dummy specimens were green and were aligned in the same dimension. The dummy protected the sample specimen from being exposed to direct hot air flow from the humidity chamber.

Four kiln runs were conducted. For the first three runs, all conditions, including sample size and measurement conditions, were the same with the exception of the drying schedule. Different drying schedules were adopted. The conditions of Run 1 were the mildest. The humidity conditions of Run 2 and Run 3 were identical, but Run 3 used a higher temperature than Run 2.

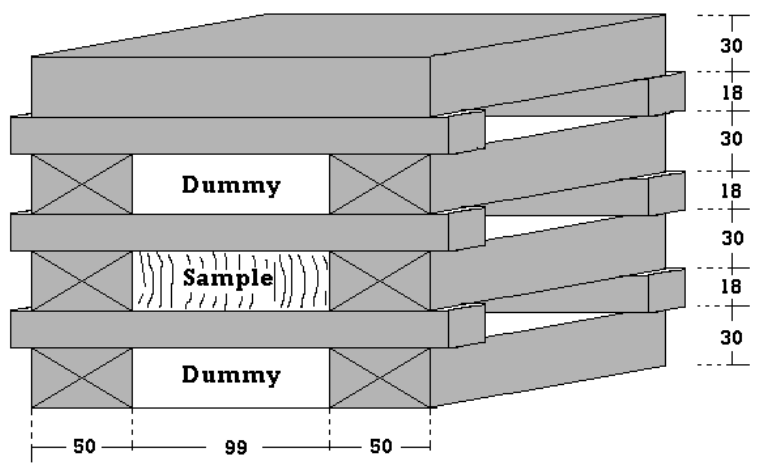

Fig. 1. Schematic diagram of a stack in the sample housing. All boards were green red oak. The unit of length is $\mathrm{mm}$.
The last kiln run (Run 4) was conducted for investigating the strain variance as a function of sample specimen width by drying one $100 \mathrm{~mm}$ or two $50 \mathrm{~mm}$ wide specimens. Its drying schedule was the same as Run 1.

The wind velocity was measured using a hot wire anemometer. Wind velocity for all drying condition was 3 to $4 \mathrm{~m} / \mathrm{s}$. After drying, the moisture content of the sample specimen was estimated by the oven drying method. The temperature of the oven was $103 \pm 2^{\circ} \mathrm{C}$. In addition, green and final moisture content were obtained from the oven dry weight. The drying schedule and moisture content of the sample specimen were as shown in Table. 1.

\section{Estimation of moisture content during wood drying}

In order to obtain consistent optical measurement, sample specimens should not be moved for weighing. However, measurement of the sample specimen weight change during the wood drying is important, thus the weight of the end-matched samples dried under the same conditions was used. Drying curves were obtained from the repeated estimation of the weight of the end-matched specimen, and the regression equations were obtained from the drying curves. The "rational one parameter" model given in equation 1 was determined from several regression equations.

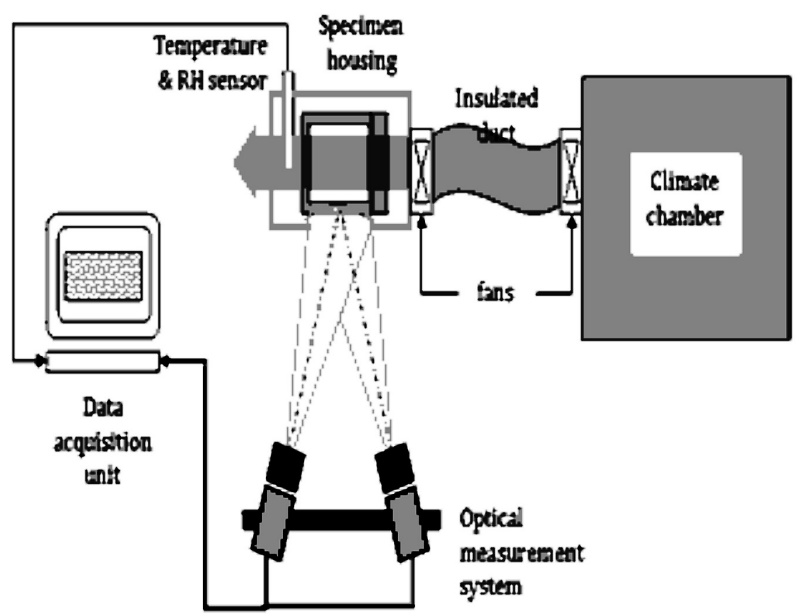

Fig. 2. Simplified diagram of the experimental apparatus: climate chamber, sample-housing and optical measurement system.

Table 1. Drying schedules of four drying runs

\begin{tabular}{|c|c|c|c|c|c|c|}
\hline Run & $\begin{array}{l}\text { Drying time } \\
\text { (days) }\end{array}$ & $\begin{array}{l}\text { Dry - bulb } \\
\text { temp. }\left({ }^{\circ} \mathrm{C}\right)\end{array}$ & RH (\%) & $\mathrm{EMC}(\%)$ & $\begin{array}{c}\text { Green MC } \\
(\%)\end{array}$ & $\begin{array}{c}\text { Final MC } \\
(\%)\end{array}$ \\
\hline \multirow{3}{*}{1} & 2 & 43.3 & 90.4 & 19.3 & \multirow{3}{*}{55.5} & \multirow{3}{*}{23.8} \\
\hline & 2 & 48.9 & 87.0 & 17.1 & & \\
\hline & 6 & 51.7 & 76.8 & 13.2 & & \\
\hline 2 & 40 & 54.4 & 30.0 & 5.2 & 50.4 & 10.0 \\
\hline 3 & 22 & 65.5 & 30.0 & 4.8 & 43.4 & 9.2 \\
\hline \multirow{3}{*}{4} & 2 & 43.3 & 90.4 & 19.3 & \multirow{3}{*}{$50.3 / 47$} & \multirow{3}{*}{$27.5 / 26.2$} \\
\hline & 2 & 48.9 & 87.0 & 17.1 & & \\
\hline & 2.5 & 51.7 & 76.8 & 13.2 & & \\
\hline
\end{tabular}




$$
U(t)=C-\frac{1}{a} \ln (1+a t)
$$

where $\mathrm{U}(\mathrm{t})$ is the moisture content at time $\mathrm{t}, \mathrm{C}$ is the initial moisture content, and a is a constant.

The moisture content of the sample specimen was calculated from measurements of initial and final moisture content, which were obtained from drying experiments and calculated using equation (1).

\section{RESULTS AND DISCUSSION}

\section{Visualization of strain distributions}

The strain distribution on a cross-sectional surface of wood can be visualized as shown in Figure 3. The strain distribution data with moisture content change are shown in Figure 4. Run 1, in which the mildest drying schedule was used, required the longest drying time needed to reach the target moisture content. Although the moisture content of the sample specimen was above the fiber saturation point, the edge of the section of board started to shrink due to the long time exposure to the heated air. On the other hand, partial shrinkage began

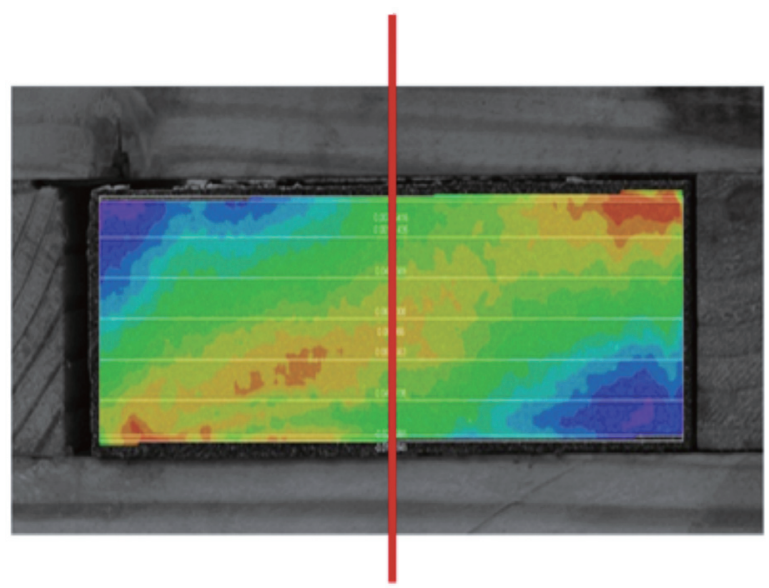

Fig. 3. A photo of a sample in a stack with a full-field strain map. The red vertical line indicates where the strain gradients along the thickness were obtained.

\begin{tabular}{|c|c|c|c|c|}
\hline \multicolumn{5}{|c|}{ Strain in tangential direction } \\
\hline & & Run 1 & Run 2 & Run 3 \\
\hline \multicolumn{2}{|c|}{$\mathrm{Tdb}\left({ }^{\circ} \mathrm{C}\right)$} & $43.3 / 48.9 / 51.7$ & 54.4 & 65.5 \\
\hline \multicolumn{2}{|c|}{$\mathrm{RH}(\%)$} & $90.4 / 87.0 / 76.8$ & 30 & 30 \\
\hline \multirow{8}{*}{$\mathrm{MC}(\%)$} & $50 \%$ & & & \\
\hline & $40 \%$ & & & \\
\hline & $35 \%$ & $\leq$ & & \\
\hline & $30 \%$ & $<\quad$ & & \\
\hline & $25 \%$ & 2 & & \\
\hline & $20 \%$ & 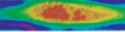 & 2 & \\
\hline & $15 \%$ & & $=$ & \\
\hline & $10 \%$ & & $z^{2}$ & 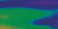 \\
\hline & & & 0.0 \\
\hline
\end{tabular}

Fig. 4. The full-field maps of strain in the tangential direction for several moisture levels.
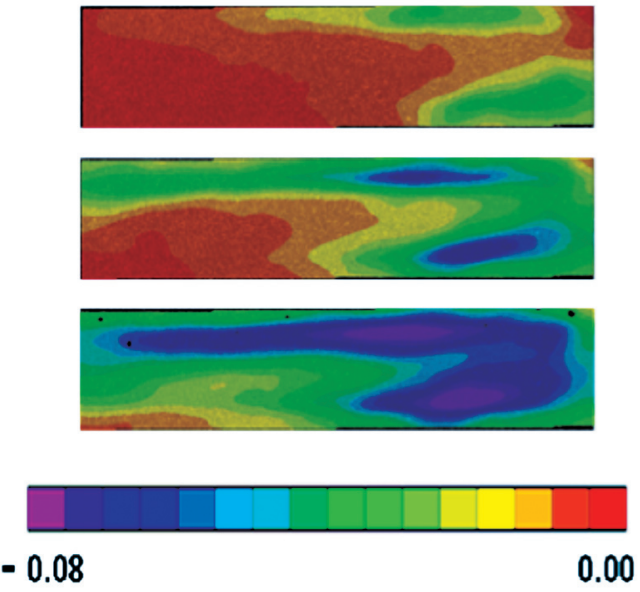

Fig. 5. The full-field maps of strain in the tangential direction for Run 3, which shows a stress reversal.

at below the fiber saturation point during Runs 2 and 3 .

As shown in Figure 3, the stress reverse position of the sample shrank more than the sample surface at a $25 \%$ moisture content in Run 1 and at a $15 \%$ moisture content in Runs 2 and 3. In addition, it is clear from the images shown in Figure 5. Although we could determine the stress reverse through DIC, estimation of the strain to stress transformation will be needed to clarify the stress reverse on wood drying as the stress and strain data do not agree.

\section{Strain change with moisture content}

The variation in the dimensional changes between the radial and tangential directions of the sample specimens as a function of moisture content are shown in Figure 6 . In the figure, e1 and e 2 refer to the mean value of all dimensional changes, which are estimated from Figure 2. Figure 6 shows the differences in the strain between the radial and tangential directions. This data suggests that the strain ratio of the tangential/radial direction is over 2 , though it is generally accepted that the T/R ratio of white oak is about 2 (Wood Handbook, 2010).

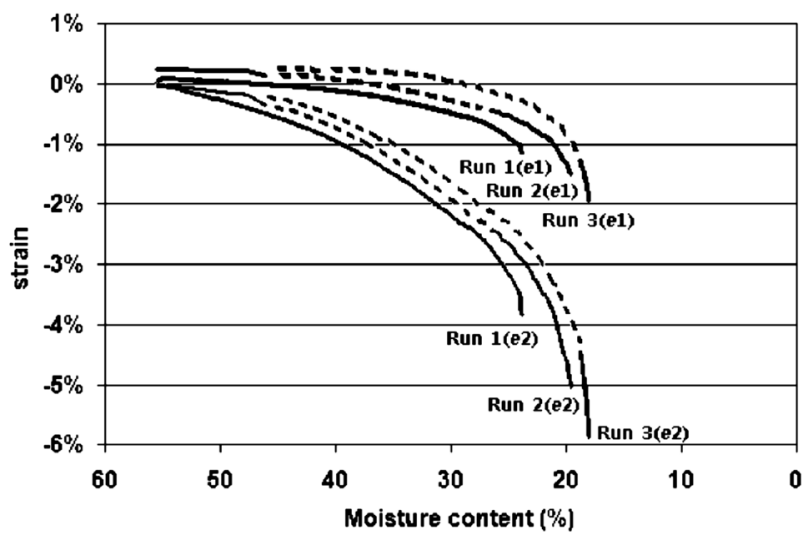

Fig. 6. Plots of the average strains of samples for three runs, which shows that the shrinkage during the mild drying schedule (Run 1) are larger than those of severe drying schedules (Runs 2 and 3). Missing data are indicated by dotted lines. 


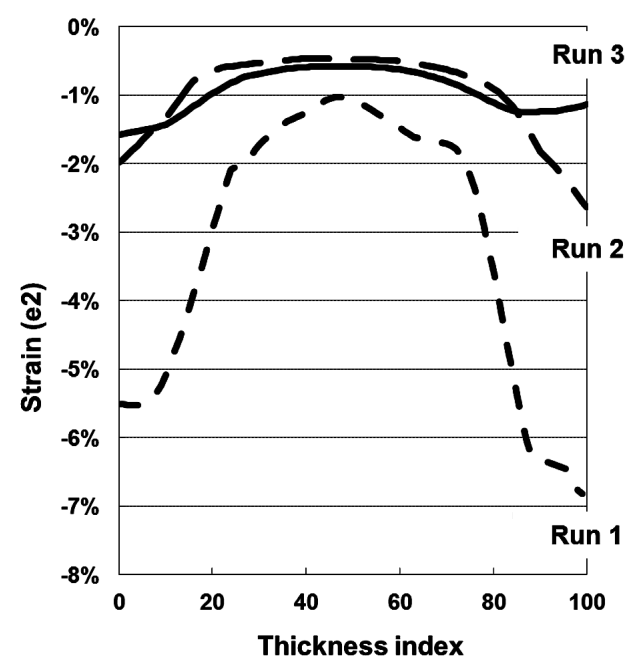

Fig. 7. Moisture distribution ratio at the center of the specimen at a moisture content of $25 \%$.

From these results, we suspect that the experimental method influenced the value of the $\mathrm{T} / \mathrm{R}$ ratio.

We compared the strain variance at a moisture content of $25 \%$ for three different drying schedules. In the case of the mild drying schedule, the strain was greater than with the severe drying schedule, as shown in Figure 7. This result showed that Run 1 had the greatest drying strain among the three drying schedules and demonstrated that the rheological deformation of wood increases during mild drying, and mild drying requires more time to reach the final moisture content.

\section{Strain ratio}

Figure 8 shows a representative strain ratio gradient in the thickness direction for the sample specimens. This

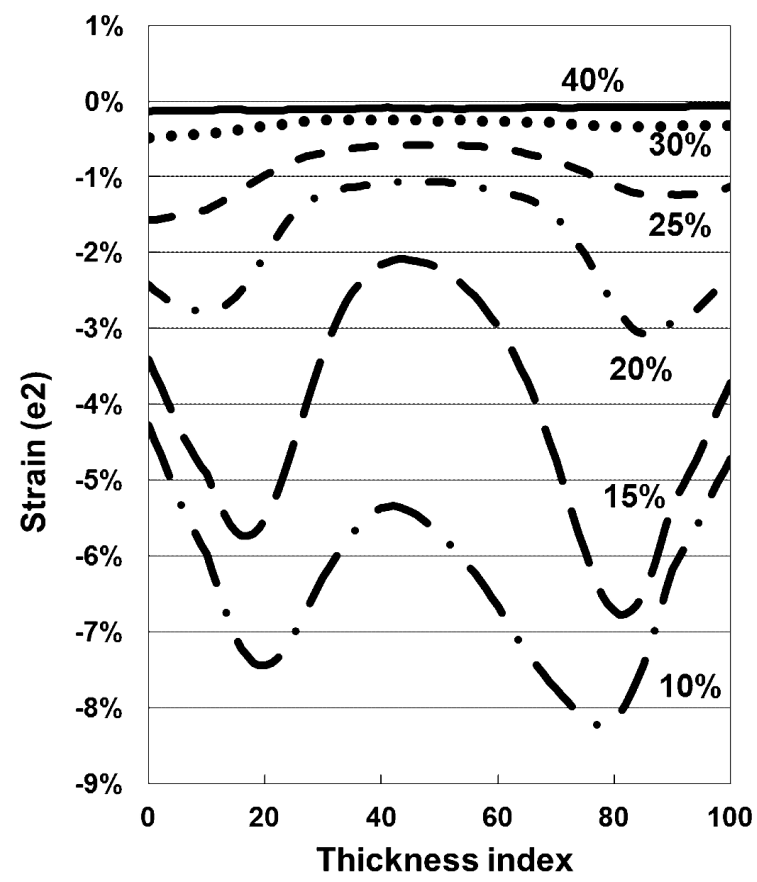

Fig. 8. Typical plots of strain gradients with thickness and moisture content for the white oak specimen.

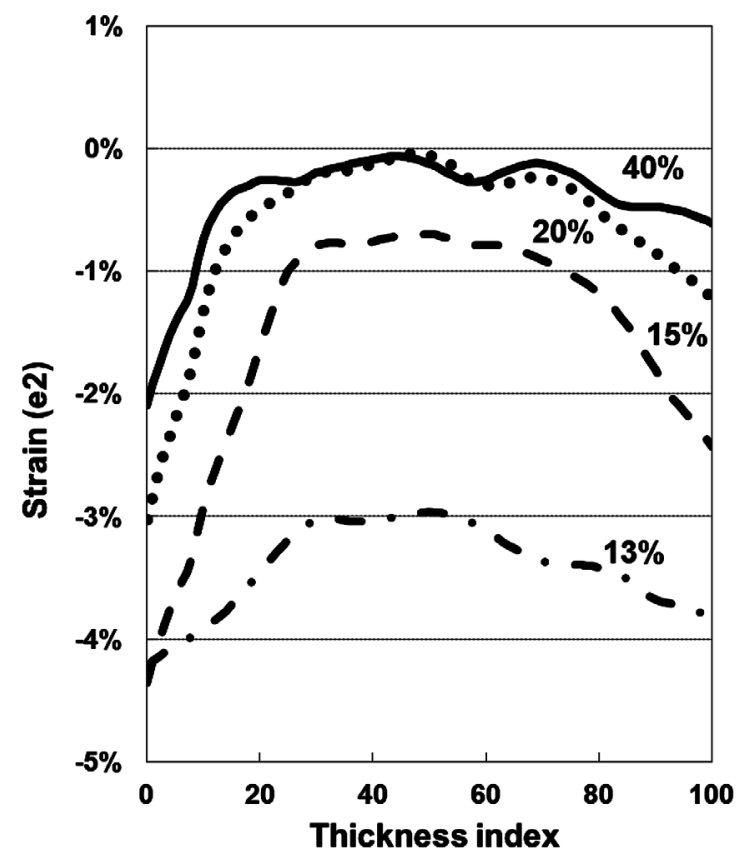

Fig. 9. Typical plots of strain gradients with thickness and moisture content for the western hemlock specimen $33 \mathrm{~mm}$ in thickness.
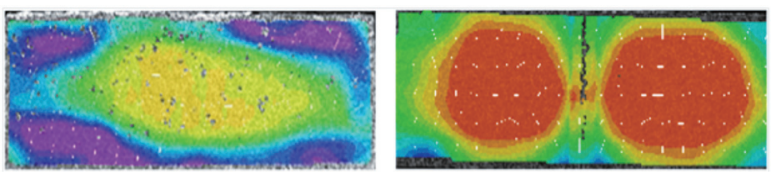

Fig. 10. Full-field maps of strain in the tangential direction for Runs 1 and 4, which used the same drying schedule. The width of the specimens used in Run 1 was twice those in for Run 4.

graph shows the center of the longitudinal sample specimen. From this figure, it is apparent that the strain gradient shows a W-shape below a 15\% moisture content. This indicates that stress reversal occurred in the direction of thickness at the surface of the sample specimen. In addition, the results confirm that the strain distributions shown in Figure 5 are related to the stress reversal.

The strain ratio gradient in the thickness direction for 33-mm-thick western hemlock specimens is shown for comparison in Figure 9. The plot of the strain ration gradient does not show a W-shape but instead is parabolic in the direction of thickness without stress reversal as western hemlock is an easy-to-dry species due to its good air and liquid permeability.

When comparing the strain ratio distributions between the $50 \mathrm{~mm}$ wide and $100 \mathrm{~mm}$ wide specimens using the same drying schedule, it can been seen that although Run 1 and Run 4 use the same drying schedule, the imminent stress ratio, which is shown as a dark blue line in Figure 9, cannot be determined for Run 4, which used a narrow 50-mm-wide board. In the case of a 100-mm-wide board, there are many dark blue areas, which indicate the imminent strain ratio. These results indicate that narrow boards have a low probability of shrinking in the direction of width during drying. 


\section{CONCLUSIONS}

We investigated the drying behavior of a refractory species, white oak, using a new methodological approach which makes use of optical measurement techniques with a digital image correlation (DIC) system. The results are summarized as follows:

Visualizing the internal strain ratio distribution of the wood using a DIC system allowed the wood drying to be accurately and continuously observed.

In Run 1, which used a mild drying schedule, stress reversal was observed at a moisture content of $25 \%$. During Runs 2 and 3, which included a more severe drying schedule, stress reversal was observed during the more intense drying conditions at a moisture content of $15 \%$.

The strains in both the tangential and radial directions were greater during the milder drying schedule than during the severe drying schedule. This result suggested that the rheological deformation of wood increased more during the mild drying condition, which required more time to reach the final moisture content.

\section{ACKNOWLEDGEMENTS}

This research was supported by the Basic Science Research Program through the National Research Foundation of Korea (NRF) funded by the Ministry of Education, Science and Technology (No. 2012004392) and the research funds of Chonbuk National University in 2011.

\section{REFERENCES}

Kang, Ho-Yang, Lech Muszyński and Michael R. Milota. 2011 a Optical Measurement of Deformations in Drying Lumber. Drying Technology 29(2): 127-134

Kang, Ho-Yang, Lech Muszyński, Michael R. Milota, Chun-Won Kang, Junji Matsumura. 2011b Preliminary Optical Measurement of Non-uniform Drying Strains and Check Formation in Drying Wood. J. Fac. Agr., Kyushu Univ. 56(2): $313-316$

Muszyński, L. 2006 Empirical Data for Modeling: Methodological Aspects in Experimentation Involving Hygromechanical Characteristics of Wood. Drying Technology 24(9): 11151120

Muszyński, L., Lagana, R., Shaler, S. M. 2006 Hygro-Mechanical Behavior of Red Spruce in Tension Parallel to the Grain. Wood and Fiber Science, 38(1): 155-165

Sakagami H., J. Matsumura and K. Oda. 2007 Shrinkage of tracheid cells with esorption visualized by confocal laser scanning microscopy. IAWA J., 28(1): 29-37

Sakagami H., J. Matsumura and K. Oda. 2009 Microcracks occurring during drying isualized by confocal laser scanning microscopy. IAWA J., $\mathbf{3 0}(2)$ : 179-187

Sakagami H., J. Matsumura and K. Oda. 2009 In-situ visualization of hardwood microcracks occurring during drying. $J$ of Wood Science, 55(5): 323-328

Schmidt, T., Tyson, J., Galanulis, K. 2002 Full-Field Dynamic Displacement and Strain Measurement Using Advanced 3-D Image Correlation Photogrammetry. Part II. Experimental Techniques, 27(4): 44-47

Wood Handbook. 2010 Forest Products Laboratory, Forest Service, USDA, Madison. p. 508 